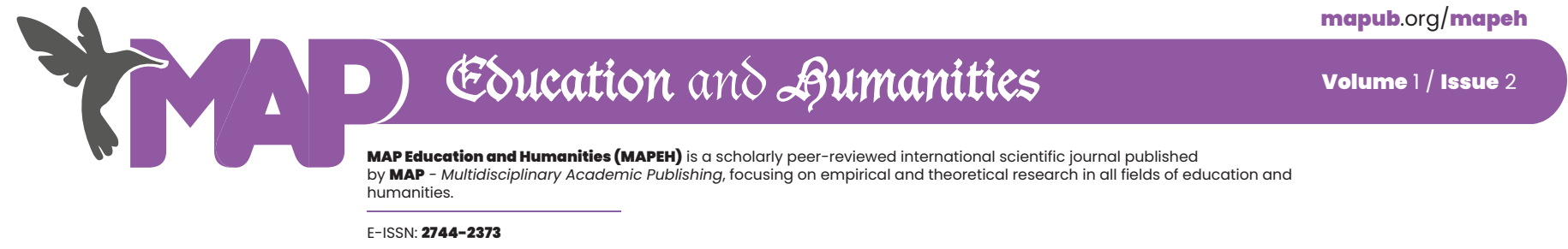

ORIGINAL RESEARCH ARTICLE

\title{
THE PLURALIZATION OF MASS NOUNS IN EUROPEAN AND ASIAN ELF
}

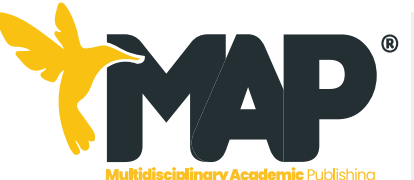

MAP EDUCATION AND HUMANITIES

Volume 1 / Issue 2

ISSN: 2744-2373/ C 2021 The Authors Published by MAP - Multidisciplinary Academic Publishing.

Article Submitted: 07 November 202 Article Accepted: 22 November 202 Article Published: 24 November 202

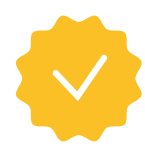

Publisher's Note: MAP stays neutral with regard to jurisdictional claims in published maps and institutional affiliations.

\author{
Isabella Tinkel ' (i) , Marie DeissI-O'Meara' ${ }^{2}$ (i) \\ 'University of Applied Sciences Burgenland, Eisenstadt, Austria \\ ${ }^{2}$ University of Applied Sciences Burgenland, Eisenstadt, Austria
}

Correspondence concerning this article should be addressed to Isabella Tinkel, University of Applied Sciences Burgenland, Eisenstadt, Austria. E-mail: isabella.tinkel@fh-burgenland.at

\section{ABSTRACT}

English has become a global lingua franca unlike any language before. This has led to the increased pragmatic use of English by an increasing number of non-native speakers and, consequently, English as a lingua franca (ELF) has emerged. It has become a contact language between speakers of different mother tongues which has led to the blurring of strict regulatory frameworks formerly established by native English varieties. ELF speakers use English in creative ways and influenced by their native languages and cultures and the imitation of the native speaker has been pushed to the background in favor of successful communication. In order to facilitate the examination of this new type of English, several ELF corpora have been established, two of which are used for this study. The Vienna-Oxford International Corpus of English (VOICE) and the Asian Corpus of English (ACE) are both collections of spoken interactions between ELF speakers that have the same size and rely on the same coding system and search parameters, which make them readily comparable. While these corpora have already aided in the discovery of several common features of ELF in general, this study focuses on the lexico-grammatical feature of the pluralization of mass nouns by either adding the ' $s$ ' or some type of quantifier in European and Asian ELF. Results show that Asian ELF speakers are less likely to pluralize mass nouns than European ELF speakers. Yet, pluralization can be found in both types of ELF and this, along with other specific, non-standard features, raises questions for English language teaching and the status of native English.

Keywords: English as a lingua franca, pluralization of mass nouns, world Englishes, European ELF, Asian ELF 


\section{Esucation and \&umanities \\ by MAP - Multidisciplinary Academic Publishing}

THE PLURALIZATION OF MASS NOUNS IN EUROPEAN AND ASIAN ELF

Isabella Tinkel and Marie Deiss/-O'Meara

\section{Introduction}

The English language has established itself as the dominant global language. This is a development that is largely due to the initial dominance of the British Empire and the subsequent gain in power of the United States of America - both countries whose official language is English (Crystal, 2013). Never before has any other language been so important in the world (of business) as English is today (Crystal, 2003). With this rapid spread of English the language itself has developed and changed and is now considered the only "genuinely global lingua franca" (Seidlhofer, 2005a) and, hence, the research field of English as a lingua franca (ELF) was established. ELF is defined as the use of English as the only language available for communication to speakers of various first languages (LI) in order to interact with each other (Crystal, 2003). It is possible, of course, that native English speakers are part of these interactions. However, since the number of non-native English speakers worldwide is considerably higher than the number of native speakers - every fourth English user - it is very likely that ELF communication takes place between people without a common mother tongue or culture. For them English functions as a contact language (Firth, 1996 as cited in Seidlhofer, 2005). As a consequence of this widespread and diverse use of English the language has been influenced significantly by non-native speakers (Dervić \& Bećirović, 2019; Crystal, 2013). This has resulted in the development of certain features that are distinctive to and common in ELF use. Generally, five categories have been proposed - phonology, lexis/lexicogrammar, grammatical features, pragmatic norms and communicative strategies (Kirkpatrick, 2010a). This research, however, focuses on one very specific feature of the lexicogrammatical area - the pluralization of mass nouns - which has been named a frequent characteristic of ELF (Jenkins et al., 2011; Kirkpatrick, 2011; Seidlhofer, 2004). By comparing two ELF corpora the Vienna Oxford International Corpus of English (VOICE) and the Asian Corpus of English (ACE) this research explores the question whether there is a difference in frequency of pluralization of mass nouns between European ELF speakers and Asian ELF speakers. The hypothesis is that the frequency of pluralization of mass nouns will be higher in Asian EFL than in European EFL.

\section{English as a Global Lingua Franca}

The underlying characteristic of ELF is that it is "an appropriate use of the resources of English for globalized purposes" (Widdowson \& Seidlhofer, 2018). This is particularly relevant in today's con- nected world where globalization and internationalization have necessitated a medium for successful and efficient communication (Yaman \& Bećirović, 2016) among speakers of different mother tongues. Thus, the general role of English for global communication cannot be rivaled by any other language spoken today and particularly ELF has become increasingly important (Jenkins et al., 2011; Smit, 2010). This significance can be exemplified using the case of interpretation within the European Union. Historically, interpreters and translators have long played an important role in ensuring successful communication in international relations between people of different mother tongues. Though interpreters are undoubtedly still important today, especially in the political domain, the great multitude of languages has made it difficult to always adhere to the originally established rules for interpreting. In the case of the EU this has meant that interpreters should only interpret into their native language. However, with the growth of the EU it has become very challenging and almost impossible to find qualified individuals (Sinanović \& Bećirović, 2016) for all possible language combinations. Thus, the regulative framework has been adapted and now interpreters work out of their mother tongue into the second language as well. In addition, English is now frequently being used, apart from its function for direct communication between individuals of different mother tongue, as a pivot language between two interpreters. This means that interpreter 1 translates from their mother tongue into English and interpreter 2 translates from English into their native tongue the target language (Seidlhofer, 2020). Hence, English gives specialists the ability to bridge the gap between people who do not speak a shared first language and enables successful communication and by functioning as a lingua franca (Seidlhofer, 2011). Such situations also drastically increase the significance of English as an international medium of communication as much information shared is transmitted through English (Melchers et al., 2019). The role that English has adopted is so unique that it has caused polarizing opinions regarding whether this development is desirable or not.

\section{ELF's Position among the World Englishes}

As has been pointed out and illustrated before, ELF makes linguistic interaction between speakers of any mother tongue possible by functioning as a bridging language. This is especially supported by researchers who support the development of new forms of English. Seidlhofer (2020) states that the growth of ELF constitutes a great opportunity for innovation and development since it is a type of English that is not controlled by native 


\section{Esucation and \&umanities \\ by MAP - Multidisciplinary Academic Publishing}

THE PLURALIZATION OF MASS NOUNS IN EUROPEAN AND ASIAN ELF

Isabella Tinkel and Marie Deiss/-O'Meara

speaker norms. This implies that inner circle Englishes (Braj Kachru, 1985), which are typically defined as native varieties being used in countries such as the United States of America, the United Kingdom, Ireland, Australia, Canada and New Zealand where English is the main official language, are no longer the only standard and benchmark for competence. In the field of ELF native speakers have lost their exclusive right to call the English language their own and to determine what can be said and what cannot be said (Widdowson, 1997 as cited in Brutt-Griffler, 2002). Consequently, English is becoming increasingly significant in both outer and expanding circle countries as they exert more influence on the development of ELF. In outer circle countries English is already used in official institutions and has great importance in multilingual settings but has not yet been adopted for private communication. In expanding circle countries English is regarded as an important international language but has no official status (Braj Kachru, 1985).

Accordingly, ELF should receive more recognition and should be accepted as creative use of language for special communicative purposes and not as a defective form of native speaker English (Jenkins et al., 2011; Seidlhofer, 2001). After all, the Englishes of the inner and outer circle are perceived as separate and valid varieties influenced by the other languages and the culture they are used in (Widdowson \& Seidlhofer, 2018). Linguistic differences between inner circle countries, such as Great Britain and America, are normally accepted without question and without one native speaker accusing the other of speaking defective English (McKay, 2002). Britain states that within the UK there is a wide variety of non-standard grammatical forms which "are the rule rather than the exception in spoken (British) English" (p.53 as cited in Kirkpatrick, 2010b). Likewise, ELF should be accepted as a kind of English that can coexist with accepted varieties. And, similar to inner and outer circle Englishes, ELF should be regarded as featuring various subtypes since it is a global phenomenon and, thus, subject to continuous change and development depending on socio-cultural and linguistic influences of the speakers (Jenkins et al., 2011). Hence, new varieties of English such as Singlish, Japlish or Hinglish have emerged and keep emerging, containing ever more creative features which deviate from inner circle standards (Nihalani, 2010). Brutt-Griffler (2002, p. 389) already suggested in 1998 that linguistic tolerance should be "extended to all English-using communities" as did Rubdy and Saraceni $(2006$, p. 13) when they stated that "importance is not given so much [...] to the application of a set of prescribed rules [...], but to tolerance for diversity and appropriacy of use in specific sociolinguistic contexts". Yet, ELF has not yet really entered people's mindsets fully and is still often regarded defective language in comparison to native speaker English (Seidlhofer, 2011).

English is no longer exclusively shaped by native speakers but, and even more, by all others who use the language (Dervić, \& Bećirović, 2020). This is sometimes regarded as problematic by inner circle societies as they feel English is their language and should remain in their hands (Saxena \& Omoniyi, 2010). New varieties such as Spanish English or Indian English give rise to the question of what is actually 'real' English (Nihalani, 2010). Some experts have been indignant about the acceptance of ELF as a separate type of English and the perceived disregard for the rules of 'real' English. Medgyes (1992), for instance, takes a very firm stance and insists that ELF must not be supported as any form of English which differs from Standard English norms but must be regarded as erroneous and is, therefore, unacceptable as a part of the varieties of the English language. Resistance to ELF might also be met in business contexts such as the example of the altered EU regulative framework for interpretation mentioned previously. ELF is sometimes perceived as a threat to interpreters', or any experts', knowledge and the consequent need for their services in certain situations. The fact that English functions as a pivot language decreases the importance of native speaker English in these contexts as no English native speakers are involved in this particular process - both interpreters being natives of the required languages at either side of the interaction (Seidlhofer, 2020).

As such, ELF is not required to remain within the bounds established through inner circle Englishes, but its users will create, develop and use this kind of English as is appropriate and necessary in certain situations. Naturally, this can be challenging considering the fact that ELF speakers come from a great variety of different cultural and linguistic backgrounds. Even Widdowson, who is a supporter of ELF, states that within its application certain "maxims could be flouted" (Widdowson \& Seidlhofer, 2018) due to speakers' unawareness of the, for example, pragmatic conventions of each other's native language. As a result, a statement that might have been intended as ironic could be taken seriously and cause significant confusion. Thus, ELF speakers should take care of how they use English to get their message across. This is especially true for high-stakes situations where, in some cases, the positive or negative result of an interaction might decide over life and death (Widdowson \& Seidlhofer, 2018). 


\section{Esucation and \&umanities \\ by MAP - Multidisciplinary Academic Publishing}

THE PLURALIZATION OF MASS NOUNS IN EUROPEAN AND ASIAN ELF

Isabella Tinkel and Marie Deiss/-O'Meara

\section{ELF Speakers' Position among Other En- glish Speakers}

Especially in the context of today's globalized (business) world, adult second language learners might be required to perform successful communicative acts rather than speak with native perfection (Rizvić \& Bećirović, 2017). Therefore, adult learners in particular, make the conscious decision to learn a new language with a special goal in mind - and this goal might be far away from achieving linguistic perfection (Bećirović, 2017; Muñoz \& Singleton, 2011; Seidlhofer, 2011). Much of the English regarded as 'correct' today is still closely tied to native speaker norms. However, this finding can and should be called into question given the global permeation of all areas of life by English (Jenkins, 2003; Seidlhofer, 2005a).

According to statistics published by Ethnologue (2021) English is spoken by $1,348,000,000$ people around the globe. Of these $370,000,000$ are native speakers while a striking $978,000,000$ are non-native speakers. With reference to the total world population this means that approximately $12 \%$ of the world's total 7.9 billion people (United Nations, 2021) speak English as a second or foreign language and around $4.5 \%$ are native speakers. This significant difference between the number of native and non-native English speakers implies that the English language is used much more frequently as a means of communication between non-native speakers (Rubdy \& Saraceni, 2006) and relatively few native speakers participate in these exchanges. Thus, the type of English spoken in ELF contexts is often relatively far removed from native speaker standards which are still deemed to be the benchmark (Muñoz \& Singleton, 2011). This means that concepts such as correctness, mistakes and language authority have been called into question (Seidlhofer, 2001). Consequently, English as a global lingua franca makes it evident that this type of English concerns everyone.

Yet, frequently, ELF users are regarded with skepticism because their usage of English may differ markedly from what is prescribed by Standard English varieties. If the aim of learning English is the approximation of the native speaker, then such judgment might be understandable. However, given that it has been suggested that ELF should not be regarded as a separate language but rather as what it is - a contact language. As such it does not require any particular rule system that ensures regularity of application of native speaker rules. Seidlhofer (2020) confirms that ELF's non-standard features are motivated by the dynamics of com- municative interaction. ELF users draw on various linguistic repertoires in order to form utterances that achieve the intended communicative purpose. It must connect people who do not have common native language or culture (Bećirović, \& Podojak, 2018; Bećirović, 2012; Firth, 1996; Seidlhofer, 2006). And as such the focus cannot, as has been pointed out before, lie on correctness, but it must be put on getting the message across and thereby being efficient and economical in language use. Thus, not the prescriptive rule system of Standard English is most important but rather the ability to express oneself appropriately in various situations is crucial (Seidlhofer, 2001). Successful pragmatic interactions despite possible misunderstandings and errors when compared to Standard English (Firth, 1996) move to the foreground. When non-native speakers communicate with each other using ELF, mistakes that would be very misleading for a native speaker might not even be noticed by the interlocutors.

In addition to using various linguistic features, ELF speakers must also acquire other skills (Jenkins, 2003). Competent users of ELF, for example, understand the art of using simple language and their multilingual resources to relate to their interlocutors. This can be done by code-switching, for instance, which facilitates the projections of cultural concepts (Jenkins et al., 2011). Confirming this, it has been found that ELF speakers are far from being "inarticulate, linguistically handicapped non-native speakers incapable of holding their own in interactions with both other non-native as well as native speakers of English" (Seidlhofer, 2020, p. 399). On the contrary, they are competent users of an "agreed-upon lingua franca [...] negotiated and shaped by all its users" (Seidlhofer, 2020, p. 399).

\section{The Countability of Nouns}

Despite the rise and ever more widely spread acceptance of ELF, the dominant perspective regarding the nature of noun countability is still that of the native English varieties. Countability refers to the grammatical feature of English (and other language) where nouns are either considered countable (count nouns) or uncountable (mass nouns). In Standard Englishes countable nouns can be quantified by denumerators and possess a morphologically distinct plural form. Generally, count nouns represent entities which are 'relatively clearly delineated concepts' such as 'table' or 'thought'. In contrast, mass nouns cannot take a denumerator, such as an indefinite article, but they can be used with certain quantifiers like 'some' or 'much'. They are also not morphologically marked 


\section{Esucation and \&umanities \\ by MAP - Multidisciplinary Academic Publishing}

THE PLURALIZATION OF MASS NOUNS IN EUROPEAN AND ASIAN ELF

Isabella Tinkel and Marie Deiss/-O'Meara

to denote plural forms. Mass nouns, refer to concepts that are a collection of miniscule entities and have no clear delineation like 'water' or 'advice'. While such features would indicate a clear distinction between English count and mass nouns, this is not so (Schmidtke \& Kuperman, 2017). Fiedler et al. (2014) state that there is no clear and transparent definition of mass and count nouns since words like 'bread' are conceptualized as solid and delineated entities but are morphologically mass nouns.

Morphologically, the plural of a noun in English is generally formed by simply adding an ' $s$ ' to the singular. There are, however, several exceptions to that rule. Nouns where the singular ends in a 'consonant $+y$ ' form the plural by substituting the ' $y$ ' with 'ies'. Yet, nouns that end in a 'vowel $+y^{\prime}$ follow the basic rule of only adding the ' $s$ '. Another category of nouns whose singular forms end in either 'sh', 'ch', 's', ' $x$ ' or ' $z$ ' make the plural by adding 'es'. The same is true for several nouns ending in ' $O$ ' but nouns ending in 'vowel $+O$ ' will form the plural by the simple addition of ' $s$ '. Besides these rather complex rules for regular plural formation, there are irregular plural forms as well. Some singular words end in ' $f$ ' or an ' $f$ ' sound and, in such cases, the plural is formed by substituting the ' $f$ ' with 'ves'. Additionally, there is the category of unpredictable irregular plurals containing singular/plural combinations such as child-children, mouse-mice or foot-feet. Conversely, there are also nouns whose morphological form does not change to express plurality, e.g. fish, deer, species (Swan, 2005).

\section{Common Features of ELF}

Mostly, ELF and any English spoken in the outer and expanding circle are not standardized like inner circle Englishes but still compared to native varieties. Meaning is frequently negotiated because ELF speakers might be influenced strongly by their mother tongue and native culture. Hence, varieties emerge which contain words and expressions that are heavily dependent on knowledge of the local language to be understood correctly. Consequently, it is not surprising that EFL is characterized by several characteristic features that distinguish it from standardized varieties of English such as those spoken in the inner circle (Melchers \& Shaw, 2003). In research ELF can be compared to either native varieties or other different ELF usages depending on location can be compared to each other. This latter aspect of local variation within ELF was mentioned by Kirkpatrick in 2004 when he asked "whether there is a separate and systematic variety of English that can thus legitimately be termed Lingua Franca English (LFE) or whether speakers use their individual linguistic resources and communicative techniques in order to communicate/negotiate meaning through whatever variety / level of English they have at their disposal" (p. 83 as cited in Kirkpatrick, 2010b). Since grammatical patters are most prominent in written language, it is difficult to detect them in the ELF which is mostly used for spoken interaction (Crystal, 2003). There are, however, some grammatical features that have been identified.

The areas of phonology, lexis/lexicogrammar, grammar, pragmatics and communicative strategies have been suggested to show the greatest potential for relatively consistent deviations in ELF from inner circle Englishes (Kirkpatrick, 2010a). Phonologically, the lack of standardized pronunciation rules within ELF is no great challenge or obstruction for communication - similar to the pronunciation differences between native varieties. Also, in today's globalized world it has become less important to sound native. Instead, the ability to communicate successfully has moved to the foreground and an ELF speaker's native accent might even serve as a welcome identity marker. While this low importance of native English pronunciation standards is beneficial to a large extent in that it may lower the anxiety threshold, it has been found that if no or very little attempt is made at imitating the native speaker, unintelligibility might be the consequence. This is particularly true for speakers of first languages that feature very different sounds compared to English or lack certain English sounds altogether (Saxena \& Omoniyi, 2010). Details on pronunciation differences can be found in Jennifer Jenkins' work (Jenkins, 2003). In the area of the lexicon, ELF is characterized by creativity and acceptance of new word forms. This can lead to creations like 'teacheress' as a female counterpart to 'teacher. While this form of creative language use does not necessarily impede communication or understanding, the usage of an inner circle English word with an entirely new meaning might do so. This may be illustrated using the case of Jamaican English where 'beverage' does not refer to drinks in general but only to one particular kind - lemonade. Another form of change in meaning might occur due to shard knowledge within a community. This is the case in Nigerian English where 'town council' refers to the department of sanitation and a 'European appointment' is a high-level white collar position (Jenkins, 2003). Constructions or words often referred to as false friends may also be employed in a meaning closer to the Ll than to the Standard English meaning. This is to say that, 'actually', meaning 'in reality' in its standard meaning, might be used to express 'current' by a German native EFL speaker because in German 'aktuell' means 'current' but looks and 


\section{Esucation and \&umanities \\ by MAP - Multidisciplinary Academic Publishing}

THE PLURALIZATION OF MASS NOUNS IN EUROPEAN AND ASIAN ELF

Isabella Tinkel and Marie Deiss/-O'Meara

sounds like 'actually' (Melchers \& Shaw, 2003). Grammatical features of ELF that have been found to occur frequently are the flexible use of quantifiers such as much and many, the disappearance of the third person ' $s$ ' in the present simple. In terms of tenses, the past tense also remains unmarked quite often and is expressed by time references, such as 'yesterday', only. Verbs that are usually classified as stative can have an -ing form in ELF and, thus, constructions like 'I'm not knowing this' are possible (Jenkins, 2003).

\section{Pluralization of Mass Nouns in ELF}

In recent years several ELF corpora have been established in order to facilitate the examination of this "kind of international communication" (Seidlhofer, 2006, 46). A 2017 study (Bostanci, 2017) examined formulaic language in European and Asian EFL interactions by using data of two ELF corpora - VOICE and ACE. It was found that, overall, European speakers of ELF used slightly more formulaic expressions than Asian ELF speakers. Non-standard forms were also examined and issues such as the present tense third person ' $-\mathrm{s}^{\prime}$, omission or overuse of prepositions and/or articles as well as pluralization were found to be problematic. This had already been confirmed earlier by Melchers and Shaw (2003) who stated that singular nouns are often pluralized. Thus, a word such as "luggage" can become "luggages" if the speaker is referring to more than one piece of luggage. This development is attributed to the relative complexity of expressing plurality by way of using additional words like piece or item. Just as the plural can be "overmarked", it can be entirely unmarked as in "I live here two year" (Jenkins 2003, p. 27). A related phenomenon was also examined by a small-scale qualitative study (Imperiani \& Mandasari, 2020) looking at lexicogrammatical features in Indonesian ELF small talk. This study did not focus on the pluralization of mass nouns but explored how plural is expressed in general. It was discovered that, instead of overusing the typical plural marker of the 's', speakers strongly tended to used the singular form of a noun (93.75\%) even though they were referring to more instances of that noun, e.g. "some of the Arabian country" or "one of the biggest organization in the world" (Imperiani \& Mandasari, 2020, p. 351). Moreover, these ELF speakers did not produce any 'incorrect' irregular plural forms which the authors ascribe to the fact that ELF speakers are aware of these types of plurals and, thus, use them like Standard English would.

Studies investigating the plural expression of mass nouns in non-inner circle English varieties have shown that the addition of the ' $\mathrm{s}$ ' is the most common strategy (Schmidtke \& Kuperman, 2017). Research by Schmied (2008, p. 198) has shown that outer circle Englishes in Kenya, Uganda and Tanzania frequently use the 's' to pluralize mass nouns as in the sentence "These advices are coming because they've already studies all of us". Pluralization by use of the indefinite article was found by Cane (1994, p. 354 as cited in Schmidtke \& Kuperman, 2017) in Brunei English giving the example of "And here's an advice for you all". In an extensive study using the world wide web as corpus through Google's advanced search function Hall et al. (2013) compared the pluralization of mass nouns by British English speakers to that of non-native English speakers from 14 countries of the outer and expanding circle of Englishes. Their findings showed significant differences between native British English spearkers' pluralization $(0.01 \%)$ and the pluralization of outer and expanding circle English speakers combined $(2.22 \%)$. Additionally, the scores for the presence of pluralization of mass nouns in outer circle countries (3.43\%) and expanding circle countries (1.01\%) was also statistically significant.

\section{Methodology}

The present study employs a descriptive analysis of the pluralization of mass nouns by examining their occurrence in two ELF corpora - VOICE and ACE. Both corpora are fully comparable as they are built along the same guidelines established and the same software developed by the VOICE team at the University of Vienna (ACE, 2014).

\section{The corpora}

The Vienna-Oxford International Corpus of English (VOICE) was created by a research team at the University of Vienna in 2009 and is the "first computer-readable corpus capturing spoken ELF interactions" (VOICE 3.0, 2021). It is an open-access resource that has been developed continuously since its inception and in September 2021 VOICE 3.0 Online was released. It contains over 1,023,082 words of "naturally-occurring, non-scripted, faceto-face" (VOICE 3.0, 2021) spoken ELF interactions between approximately 753 individual speakers of 49 different first languages. Even though EFL interactions may also involve native speakers of English the number of these included in VOICE data is very low at only $7 \%$. VOICE is subdivided into three domains - leisure (10\%), education (25\%) and professional $(65 \%)$ - whereby the professional domain contains the three sub-domains of business (20\%), organizational (35\%) and research and science $(10 \%)$. Throughout all these domains nine different 


\section{Esucation and \&umanities \\ by MAP - Multidisciplinary Academic Publishing}

THE PLURALIZATION OF MASS NOUNS IN EUROPEAN AND ASIAN ELF

Isabella Tinkel and Marie Deiss/-O'Meara

speech event types are distinguished - conversation, interview, meeting, panel, press conference, question-answer session, seminar discussion, service encounter, working group discussion and workshop discussion (VOICE 3.0, 2021).

The Asian Corpus of English was created by the University of Hong Kong and completed in 2014. It includes one million words of natural spoken ELF interactions in Asia. Like VOICE it is subdivided into the domains of leisure (10\%), education (25\%) and professional (65\%) - whereby the professional domain contains the three sub-domains of business (20\%), organizational (35\%) and research and science $(10 \%)$. Speech event types also correspond largely to those used in the VOICE project. This similarity is due to the fact that ACE was developed using the same software as VOICE and in order to be able to compare European and Asian ELF (ACE, 2014).

In order to test the hypothesis that the frequency of pluralization of mass nouns will be higher in Asian EFL than in European EFL, VOICE and ACE were searched for occurrences of English mass nouns used as countable nouns.

The uncountable nouns included in this research were adopted from Swan's (2005, p. 129) and Hall et al.'s (2013) list of the most common uncountable nouns. The result are the following 43 search terms: accommodation, advice, applause, baggage, bread, cash, chess, chewing gum, corruption, dew, employment, equipment, evidence, feedback, fun, furniture, hardware, homework, information, jewellery, knowledge, lightning, luck, luggage, magic, money, news, permission, poetry, progress, publicity, research, rubbish, slang, software, thunder, traffic, underwear, violence, vocabulary and work.

In addition, 'people' and 'damage' which are often used with a plural 's' but, in contrast to the words featured in the list above, actually exist in that form but with an entirely different meaning to the singular version, were included in the research by the authors based on their experience as English teachers.

\section{Data Analysis}

For each noun the number of total occurrences (including 'false' plurals) was recorded. Then frequency of 'incorrectly' pluralized nouns was recorded for each term and subdivided into two categories - pluralization by using the 's' or 'ies' marker or by use of the indefinite article or any other quantifier. These numbers were used to calculate the percentage of pluralized mass nouns for each item and overall.

\section{Results and Discussion}

The analysis of the data has led to the rejection of the hypothesis. Asian ELF features fewer instances of pluralization of mass nouns compared to European ELF. Overall, European EFL speakers pluralized $5.76 \%$ of the total number $(n=2414)$ of all instances of the mass nouns analyzed, whereas Asian EFL speakers only pluralized $2.54 \%$ of that total number $(n=2281)$. This contradicts the findings of Bostanci's (2017) study comparing VOICE and ACE which found that Asian ELF featured more mass nouns that were treated as countable nouns when compared to European ELF.

\section{Figure 1:}

$\%$ of pluralized mass nouns of total occurrences

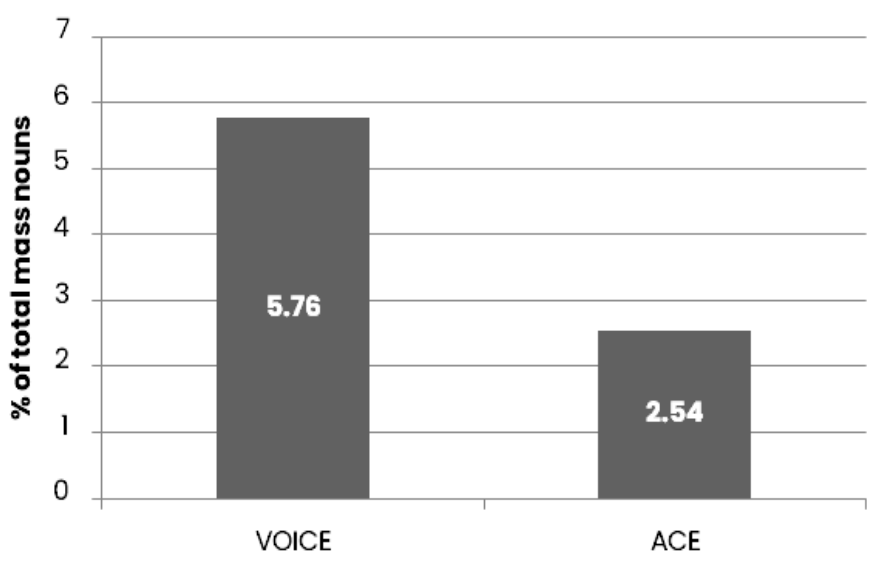

The examination of the dataset in more depth revealed that there are notable differences between the two corpora regarding the pluralization of certain words and is summarized in Table 1. Out of the 43 items checked in each corpus European ELF speakers' percentages of pluralization exceed those of Asian ELF speakers in 16 cases. However, in 10 of those cases no pluralization was found in Asian ELF but was detected in European ELF. Conversely, Asian ELF speakers pluralized a larger percentage of nouns in 10 cases, whereby 5 of these showed no pluralization in European ELF. It has to be mentioned that some of the words checked could not be found in the corpus at all. 


\section{esucation and doumanities \\ by MAP - Multidisciplinary Academic Publishing}

THE PLURALIZATION OF MASS NOUNS IN EUROPEAN AND ASIAN ELF

Isabella Tinkel and Marie Deissl-O'Meara

Table 1:

Total occurrences and \% or pluralization in VOICE and ACE

\begin{tabular}{|c|c|c|c|c|}
\hline & VOICE total & VOICE pluralized & ACE pluralized & ACE total \\
\hline accommodation & 6 & 16.7 & 16.7 & 6 \\
\hline advice & 33 & 12.1 & & 8 \\
\hline applause & & & 33.3 & 6 \\
\hline \multicolumn{5}{|l|}{ baggage } \\
\hline bread & 19 & 5.26 & 8.0 & 25 \\
\hline cash & 19 & & & 7 \\
\hline chess & 2 & & & \\
\hline \multicolumn{5}{|l|}{ chewing gum } \\
\hline corruption & 16 & & & 9 \\
\hline damage & 7 & 14.3 & 33.3 & 3 \\
\hline \multicolumn{5}{|l|}{ dew } \\
\hline employment & 88 & 4.55 & & 20 \\
\hline equipment & 8 & & 14.3 & 7 \\
\hline evidence & 26 & & 18.5 & 27 \\
\hline feedback & 58 & 5.17 & & 24 \\
\hline fun & 81 & 1.23 & & 17 \\
\hline furniture & 5 & & 11.1 & 9 \\
\hline hardware & 2 & & & 1 \\
\hline homework & 14 & 7.14 & & 11 \\
\hline information & 400 & 1.25 & 3.77 & 106 \\
\hline jewellery & 1 & & & 2 \\
\hline knowledge & 196 & 7.14 & 5.17 & 58 \\
\hline lightning & 1 & & & \\
\hline luck & 29 & 13.8 & 20.0 & 5 \\
\hline luggage & 6 & 33.3 & & 1 \\
\hline magic & 1 & & & 7 \\
\hline money & 469 & 1.71 & 0.35 & 285 \\
\hline news & 67 & 10.4 & & 37 \\
\hline permission & 9 & 11.1 & 10.0 & 10 \\
\hline people & 21 & 95.2 & 1.21 & 1160 \\
\hline poetry & & & & 2 \\
\hline progress & 43 & 6.98 & 8.33 & 12 \\
\hline
\end{tabular}




\section{Eoveation and \&umanities \\ by MAP - Multidisciplinary Academic Publishing}

THE PLURALIZATION OF MASS NOUNS IN EUROPEAN AND ASIAN ELF

Isabella Tinkel and Marie Deiss/-O'Meara

\begin{tabular}{|l|c|c|c|c|}
\hline publicity & 22 & $\mathbf{1 3 . 6}$ & 0.00 & 1 \\
\hline research & 233 & $\mathbf{5 . 1 5}$ & 2.08 & 96 \\
\hline rubbish & 2 & & 20.0 & 5 \\
\hline slang & 2 & & 20.0 & 5 \\
\hline software & 8 & & $\mathbf{9 . 0 9}$ & 11 \\
\hline thunder & & & & 2 \\
\hline traffic & 18 & $\mathbf{2 7 . 8}$ & & 14 \\
\hline underwear & 24 & $\mathbf{4 . 1 7}$ & & 11 \\
\hline violence & 9 & & $\mathbf{1 4 . 3}$ & 21 \\
\hline vocabulary & $\mathbf{4 6 7}$ & $\mathbf{8 . 1 4}$ & 4.80 & 250 \\
\hline work & $\mathbf{2 4 1 4}$ & & & $\mathbf{2 2 8 1}$ \\
\hline
\end{tabular}

When exploring the pluralization of those items that featured in both corpora, the difference in frequency of pluralization is most striking for the word 'people'. European ELF speakers were found to pluralize $95.24 \%$ of all occurrences $(n=21)$ of the item, while Asian ELF speakers only used the item as countable noun in $1.21 \%$ of the times $(n=1160)$ it was used. European ELF also uses 'traffic' as a countable noun in $27.78 \%$ of the cases $(n=18)$, while Asian ELF does not do so at all despite the word being present in the corpus for an almost equal number of instances $(n=14)$. For 'information' it can be observed that Asian ELF speakers pluralized this word more often than European ELF speakers with $3.77 \%$ $(n=106)$ compared to $1.24 \%(n=400)$. In terms of two items that can be found with similar frequency in both corpora 'equipment' and 'evidence' stand out. In both cases Asian ELF shows pluralization while European ELF does not. In the ACE 'equipment' was pluralized $14.29 \%(n=7)$ and 'evidence' $18.52 \%$ $(n=27)$ while VOICE contains these items -8 and 26 instances respectively - but does not feature any pluralization. A common understanding seems to exist between European and Asian ELF speakers regarding the non-pluralization of certain words such as 'cash', 'corruption', 'hardware', 'jewellery' and 'magic' since they are featured in both corpora but never pluralized. Figure 2 below visualizes the data given in the table excluding the items that were either not present in both corpora or where no pluralization of mass nouns could be found.

\section{Figure 2:}

$\%$ of pluralization in VOICE and ACE

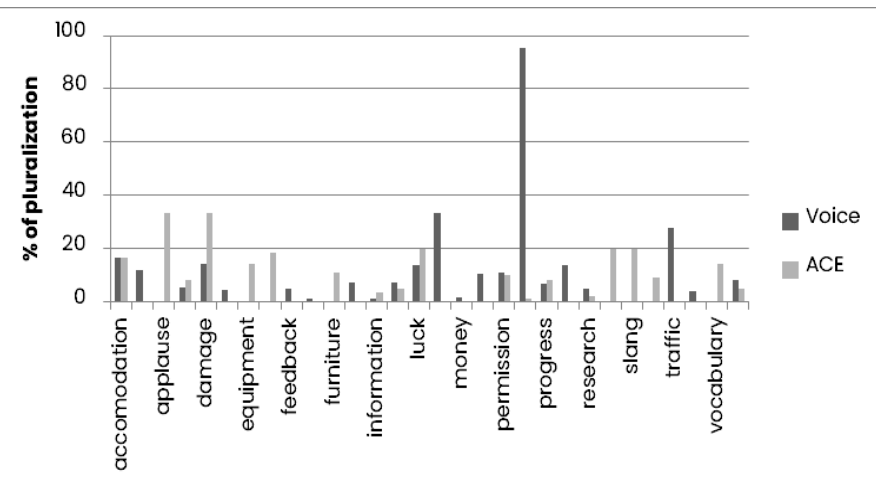

In terms of the fashion of pluralization by either the addition of an ' $s$ ' or by using an type of quantifier, Asian ELF speakers used the ' $s$ ' to express plural in 24 cases $(41.38 \%)$ out of a total of 58 cases of pluralization compared to European ELF speakers' usage of the 's' in 60 cases (43.17\%) out of 139 total instances. Although the percentages are quite similar, a possible explanation of Asian ELF featuring slightly fewer ' $s$ ' pluralizations may be that many Asian languages do not use inflection (Kortmann, 2010; Takeshita, 2010 as cited in Bostanci, 2017) and, thus, Asian ELF speakers might have a lower inclination to add the additions ' $s$ ' to a mass noun. Asian ELF features slightly more instances of pluralization by usage of a quantifier such as the indefinite article or 'many' with 34 instances (58.62\%) out of a total 58. European ELF, in contrast shows 79 cases (56.83\%) of pluralization by way of quantifying out of a total of 139 instances. This would not align with 


\section{Esucation and \&umanities \\ by MAP - Multidisciplinary Academic Publishing}

THE PLURALIZATION OF MASS NOUNS IN EUROPEAN AND ASIAN ELF

Isabella Tinkel and Marie Deiss/-O'Meara

the fact that articles are absent in many Asian languages (Kortmann, 2010; Takeshita, 2010 as cited in Bostanci, 2017) which might contribute to the less frequent pluralization through articles or quantifiers.

\section{Figure 3:}

Number and \% of pluralizations by 's' or 'quantifier' in VOICE and ACE

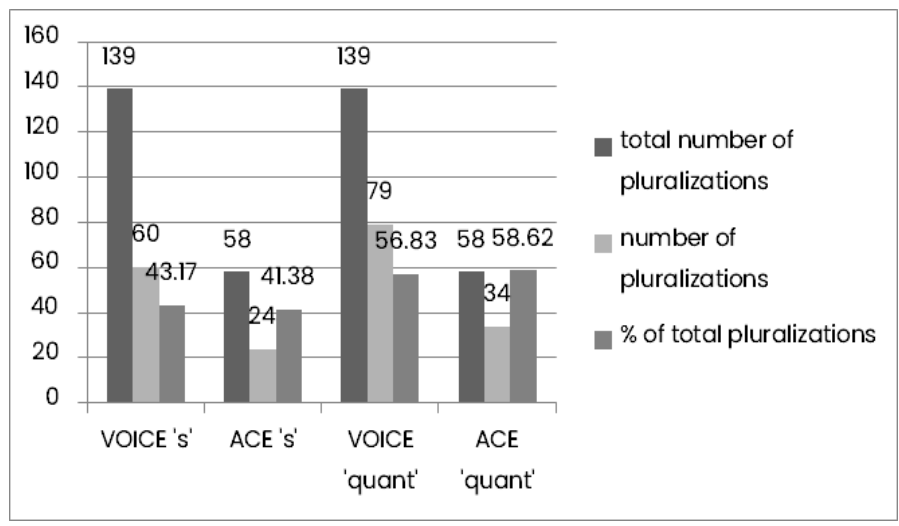

\section{Conclusion}

The results of the present study clearly show that the pluralization of mass nouns is more frequent in European EFL than Asian ELF - at least within the spoken interactions contained in VOICE and ACE and the selected set of mass nouns used. Naturally, more data and subsequent analysis would be required to confirm or refute the results. Possibilities to do so would be the inclusion of the English as a Lingua Franca in Academic Settings (ELFA) corpus developed by Anna Mauranen (2003) at the University of Helsinki. Alternatively, the present research design could be reapplied using a wider selection of mass nouns perhaps including those that only exist in a 'plural form' with the 's' as standard, such as 'scissors' or 'trousers'. Such a project would be interesting since the issue of pluralization in ELF in general has been examined (e.g. Bostanci, 2017; Schmidtke \& Kuperman, 2017) and European ELF and Asian ELF have been examined using VOICE and ACE (Bostanci, 2017; Kirkpatrick, 2013), but the specific topic of differences in pluralization of mass nouns has not received much attention. Kirkpatrick (2013) lists several common features of European and Asian ELF when compared to standard varieties - the pluralization of mass nouns among them - but does not give concrete information regarding the occurrence of this feature in either VOICE or ACE.

Given the fact that ELF and its non-standard features are a reality in a globalized, connected world, it has been deemed prudent to consider changing the attitude towards it in the field of ed- ucation. English is in great demand but learners' goals are mostly not the imitation of the native standard but the ability to communicate successfully (Delić \& Bećirović, 2018). It has been suggested, therefore, that English might be viewed not as a foreign language per se any longer but recognized as a "co-existent and non-competitive addition to the learner/user's linguistic repertoire" (Seidlhofer, 2020 , p. 401). This would remove English from competition with other foreign languages being learnt/ taught and, thus, 'smaller' languages would no longer perceive English as a threat to their existence. Moreover, native speaker teachers might no longer be the 'be all and end all'. Kirkpatrick suggests that "the local, well-trained and culturally aware teacher whose English language proficiency is high represents the more appropriate English teacher than does the native speaker" $(2013$, p. 27) - a concept that is still rather uncommon but should be considered (Jenkins, 2003; Seidlhofer, 2005b) despite nativelikeness remaining the most frequent benchmark for assessment of competence (Muñoz \& Singleton, 2011). However, such a change has not yet been reflected in, for instance, the documents issued by the Language Policy division of the Council of Europe. The level and skills descriptors still target the non-native speaker's ability to approximate the native speaker to a certain extent at a given stage in the learning process (Seidlhofer, 2020). Yet, non-standard uses such as the pluralization of mass nouns might and should gain more acceptance (Seidlhofer, 2001; Widdowson, 1997 as cited in Brutt-Griffler, 2002) as different language communities are creating their own versions of English and these types of English spread across the globe through international exchange (Crystal, 2013).

Conflict of interest: Isabella Tinkel and Marie Deissl-O'Meara declare that they have no conflict of interest.

\section{References}

ACE. (2014). The Asian Corpus of English. https://corpus.eduhk.hk/ace/index.html

Bećirović, S., \& Podojak, S., (2018). Intercultural Development of Bosnian University Students Through Foreign Language Learning. European Researcher, 9(2), 68-77. DOI: 10.13187/er.2018.2.68

Bećirović, S. (2017). The Relationship between Gender, Motivation and Achievement in Learning English as a Foreign Language. European Journal of Contemporary Education, 6(2), 210-220.

Bećirović, S., (2012). The Role of Intercultural Education in Fostering Cross-Cultural Understand- 


\section{Esucation and diumanities \\ by MAP - Multidisciplinary Academic Publishing \\ THE PLURALIZATION OF MASS NOUNS IN EUROPEAN AND ASIAN ELF \\ Isabella Tinkel and Marie Deiss/-O'Meara}

ing. Epiphany Journal of Transdisciplinary Studies, 5(1), 138-156. DOI: 10.21533/epiphany.v5i1.49

Bostanci, T. (2017). The use of formulaic language in Asian and European ELF contexts: A corpus based study. Ihsan Doğramacı Bilkent University.

Brutt-Griffler, J. (2002). World English. Multilingual Matters.

Crystal, D. (2003). English as a Global Language. Cambridge University Press.

Crystal, D. (2013). Will English Always Be the Global Language? British Council Serbia. https:// www.youtube.com/watch?v=5Kvs8SxN8mc

Delić, H., \& Bećirović, S., (2018). The influence of Grade Point Average and Socioeconomic Status on Learning Strategies, Journal of Education and Humanities, 1(2), 53-64, http://dx.doi.org/10.14706/ jeh2018123

Dervić, M., \& Bećirović, S. (2019). Native and Non-Native EFL Teachers Dichotomy: Terminological, Competitiveness and Employment Discrimination. Journal of Language and Education, 5(3), 114-127. https://doi.org/10.17323/jle.2019.9746

Dervić, M., \& Bećirović, S. (2020). Prerogative of the Lexical Approach in Communicative Language Teaching, European Journal of Education Studies, 7(3), 1-13. doi: 10.5281/zenodo.3748039Ethnologue. (2021). What is the most spoken language? https://www.ethnologue.com/guides/ most-spoken-languages

Fiedler, N., Nickels, L., \& Biedermann, B. (2014). Representation and processing of mass and count nouns: A review. Frontiers in Psychology, 5,589 .

Firth, A. (1996). The discursive accomplishment of normality. On "lingua franca" English and conversation analysis. Journal of Pragmatics, 26, 237-259.

Hall, C. J., Schmidtke, D., \& Vickers, J. (2013). Countability in world Englishes. World Englishes, $32(1), 1-22$.

Imperiani, E. D. A., \& Mandasari, H. A. (2020). Lexicogrammatical Features of ELF Speakers in an Asian Students Association Small Talk in Indonesia. 424(Icollite 2019), 346-352. https://doi.org/10.2991/ assehr.k.200325.109
Jenkins, J. (2003). World Englishes. A resource book for students. Routledge.

Jenkins, J., Cogo, A., \& Dewey, M. (2011). Reviews of developments in research into English as a lingua franca. Language Teaching, 44(3), 281-315.

Kachru, B. (1985). Standard, Codification and Sociolinguistic Realism: The English Language in the Outer Circle. In R. Quirk \& H. Widdowson (Eds.), English in the World: Teaching and Learning the Language and Literature (pp. 11-30). Cambridge University Press.

Kirkpatrick, A. (2010a). English as a Lingua Franca in ASEAN: A Multilingual Model. Hong Kong University Press.

Kirkpatrick, A. (2010b). Researching English as a Lingua Franca in Asia: the Asian Corpus of English (ACE) project. Exploring New Dimensions in Asian Englishes, 4-19. https://linkinghub.elsevier. com/retrieve/pii/s2213177918309417

Kirkpatrick, A. (2011). English as an asian lingua franca and the multilingual model of ELT. Journal of Language Teaching, 1-13.

Kirkpatrick, A. (2013). The Asian Corpus of English: motivation and aims. Learner Corpus Studies in Asia and the World, 1, 17-30.

Mauranen, A. (2003). Academic English as lingua franca - a corpus approach. TESOL Quarter$l y, 37,513-527$.

McKay, S. L. (2002). Teaching English as an International Language: Rethinking Goals and Approaches. Oxford University Press.

Medgyes, P. (1992). Native or non-native: Who's worth more? ELT Journal, 46, 340-349.

Melchers, G., \& Shaw, P. (2003). World Englishes. Arnold.

Muñoz, C., \& Singleton, D. (2011). A critical review of age-related research on L2 ultimate attainment. In Language Teaching. https://doi. org/10.1017/s0261444810000327

Nihalani, P. (2010). Globalization and International Intelligibility. In M. Saxena \& T. Omoniyi (Eds.), Contending with Globalization in World Englishes (pp. 23-44). Multilingual Matters. 


\section{Esucation and \&umanities \\ by MAP - Multidisciplinary Academic Publishing}

THE PLURALIZATION OF MASS NOUNS IN EUROPEAN AND ASIAN ELF

Isabella Tinkel and Marie Deiss/-O'Meara

Rizvić E., \& Bećirović, S., (2017). Willingness to Communicate in English as a Foreign Language in Bosnian-Herzegovinian EFL Context. European Researcher, 8(3), 224-235. doi: 10.13187/er.2017.3.224

Rubdy, R., \& Saraceni, M. (2006). Introduction. In R. Rubdy \& M. Saraceni (Eds.), English in the World: Global Rules, Global Roles (pp. 5-16). Continuum

Saxena, M., \& Omoniyi, T. (2010). Contending with Globalization in World Englishes (M. Saxena \& T. Omoniyi (eds.)). Multilingual Matters.

Schmidtke, D., \& Kuperman, V. (2017). Mass counts in World Englishes: A corpus linguistic study of noun countability in non-native varieties of English. In Corpus Linguistics and Linguistic Theory (Vol. 13, Issue 1). https://doi.org/10.1515/cllt-20150047

Schmied, J. (2008). 12 East African Englishes. In B. Kachru, Y. Kachru, \& C. L. Nelson (Eds.), The Handbook of World Englishes (pp. 188-202). Blackwell Publishers.

Seidlhofer, B. (2001). Closing a conceptual gap: the case for a description of English as a lingua franca. International Journal of Applied Linguistics, $11(2)$.

Seidlhofer, B. (2004). Research perspectives on teaching English as a lingua franca. Annual Review of Applied Linguistics, 24, 209-223.

Seidlhofer, B. (2005a). English as a lingua franca. ELT Journal, 59(4), 339-341. https://doi. org/10.1093/elt/cci064

Seidlhofer, B. (2005b). English as a lingua franca. In A. S. Hornby (Ed.), Oxford advanced learner's dictionary of current English (7th ed., pp. 133-158). Oxford University Press, R92.

Seidlhofer, B. (2006). English as a Lingua Franca in the Expanding Circle: What it Isn't. In R. Rubdy \& M. Saraceni (Eds.), English in the World: Global Rules, Global Roles (pp. 40-50). Continuum.

Seidlhofer, B. (2011). Understanding English as a Lingua Franca. Oxford University Press.

Seidlhofer, B. (2020). English as a lingua franca in the European context. In A. Kirkpatrick (Ed.), The Routledge handbook of World Englishes (2nd ed., pp. 389-407). Routledge.

Sinanović, J., \& Bećirović, S. (2016). The
Determinants of Lifelong Learning. European researcher, 103(2), 107-118. doi: 10.13187/er.2016.103.107

Smit, U. (2010). English as a lingua franca in higher education: a longitudinal study of classroom discourse. Mouton de Gruyter.

Swan, M. (2005). Practical English Usage (Third). Oxford University Press.

United Nations. (2021). Worldometer. https://www.worldometers.info/world-population/

VOICE 3.0. (2021). Vienna-Oxford Internation Corpus of English. https://voice3.acdh.oeaw.ac.at

Widdowson, H., \& Seidlhofer, B. (2018). The TEFLology Podcast. https://www.youtube.com/ watch?v=wo4FNTb_ZsU

Yaman, A. \& Bećirović, S. (2016). Learning English and Media Literacy. Imperial Journal of Interdisciplinary Research (IJIR), 2(6), 660-663. 